This article has been accepted for publication in Thorax following peer review. The definitive copyedited, typeset version Moodie C, Looking beyond the smoke and mirrors, Thorax, 2021;76:2. is available online at: https://doi.org/10.1136/thoraxjnl-2020-216302

(C) Authors (or their employer(s)) 2021. Reuse of this manuscript version (excluding any databases, tables, diagrams, photographs and other images or illustrative material included where a another copyright owner is identified) is permitted strictly pursuant to the terms of the Creative Commons Attribution-NonCommercial 4.0 International (CC-BY-NC 4.0) http://creativecommons.org/licenses/by-nc/4.0/

\title{
Looking beyond the smoke and mirrors
}

For more than a quarter of a century, tobacco companies have argued that plain packaging will increase sales of counterfeit cigarettes. ${ }^{1}$ The claim, that if all packs look the same they would be easier for criminals to copy and lower the cost to, and confuse, the public, who would be less able to distinguish fake from legitimate packs, seems credible. However, the presence of full branding is no barrier to duplicating cigarette packs, and the cost per pack for mass produced counterfeit cigarettes is so low that plain packaging could not reduce the price paid by consumers. ${ }^{2}$ As for confusion among the public, counterfeit cigarettes are generally significantly cheaper than legitimate products; typically sold 'under the counter', in markets or non-retail settings; often have inferior quality packs and sticks; and contain poor tasting tobacco. Price, place of purchase, pack and stick appearance, and product performance, signal authenticity. ${ }^{2}$ For non-counterfeit illicit tobacco, the presence of full branding is a giveaway.

Laverty et al, ${ }^{3}$ using Eurobarometer data, found no significant increase between 2015 and 2018 in consumers being offered illicit tobacco in three European countries that introduced plain packaging during this period (UK, Ireland, France). Research on illicit use is needed however, as it is with respect to the recent ban on characterising flavours in cigarettes, which entered into force across much of Europe in May 2020. As the ban will change the taste of the product for flavoured cigarette smokers, the primary reason for using flavoured cigarettes, ${ }^{4}$ monitoring the impact on the illicit market is imperative. Plain packaging may actually offer an opportunity to reduce illicit trade. In countries with this policy, the legislation stipulates that cigarette sticks must have white cigarette paper devoid of any markings, other than a brand variant name or alphanumeric code in small font near the filter.

Plain packaging creates a canvas on which markings or messaging could be placed to help identify illicit cigarettes. This is already a requirement in Singapore, where tobacco companies must display the letters Singapore Duty Paid Cigarettes (SDPC) on each cigarette stick. An alternative would be to use the stick to communicate the risks of smoking. Warnings on cigarette sticks would fulfil the same role as the letters SDPC while simultaneously prolonging health messaging to the point of consumption; particularly important for youth, who are not necessarily exposed to on-pack warnings when first trying a cigarette. A warning on each stick would function as an overt security marking, helping differentiate them from illicit cigarettes, except for counterfeits, at least where counterfeiters 
Moodie C (2021). Looking beyond the smoke and mirrors. Thorax, 76, 2.

include warnings on sticks. Just as cigarette packs in the UK and EU must also include semicovert and covert security markings, these additional levels of authentication are feasible for warnings on cigarette sticks. It may be possible to include, within the warning text, microprinting (identifiable with magnification) as a semicovert marking, and a safe to consume taggant (a microscopic machine-readable chemical marker) ${ }^{5}$ as a covert marking. With illicit tobacco depriving governments and the tobacco industry of revenue, warnings on cigarette sticks may be one means of tackling the problem.

\section{REFERENCES}

1 Evans-Reeves K, Hatchard J, Rowell A, et al. Illicit tobacco trade is 'booming': UK newspaper coverage of data funded by transnational tobacco companies. Tob Control 2020;29:78-86.

2 Moodie C, Purves R, Mckell J, et al. Young women smokers' perceptions and use of counterfeit cigarettes: Would plain packaging make a difference? Addict Res Theory 2014;22:263-70.

3 Laverty AA, Millett C, Hopkinson NS, et al. Introduction of standardised packaging and availability of illicit cigarettes: a difference-in-difference analysis of European Union survey data 2015-2018. Thorax 2021;76:91-3.

4 Moodie C, MacKintosh AM, Thrasher JF, et al. Use of cigarettes with Flavor-changing capsules among smokers in the United Kingdom: an online survey. Nicotine Tob Res 2019;21:1547-55.

5 Rey CM. Is marking individual doses the future of anticounterfeiting? 2017. Available: www.lifescienceleader.com/doc/is-marking-individual-doses-the-future-of-anticounterfeiting$\underline{0001}$

\section{Author: Crawford Moodie, Institute for Social Marketing and Health, University of Stirling. c.s.moodie@stir.ac.uk}

